
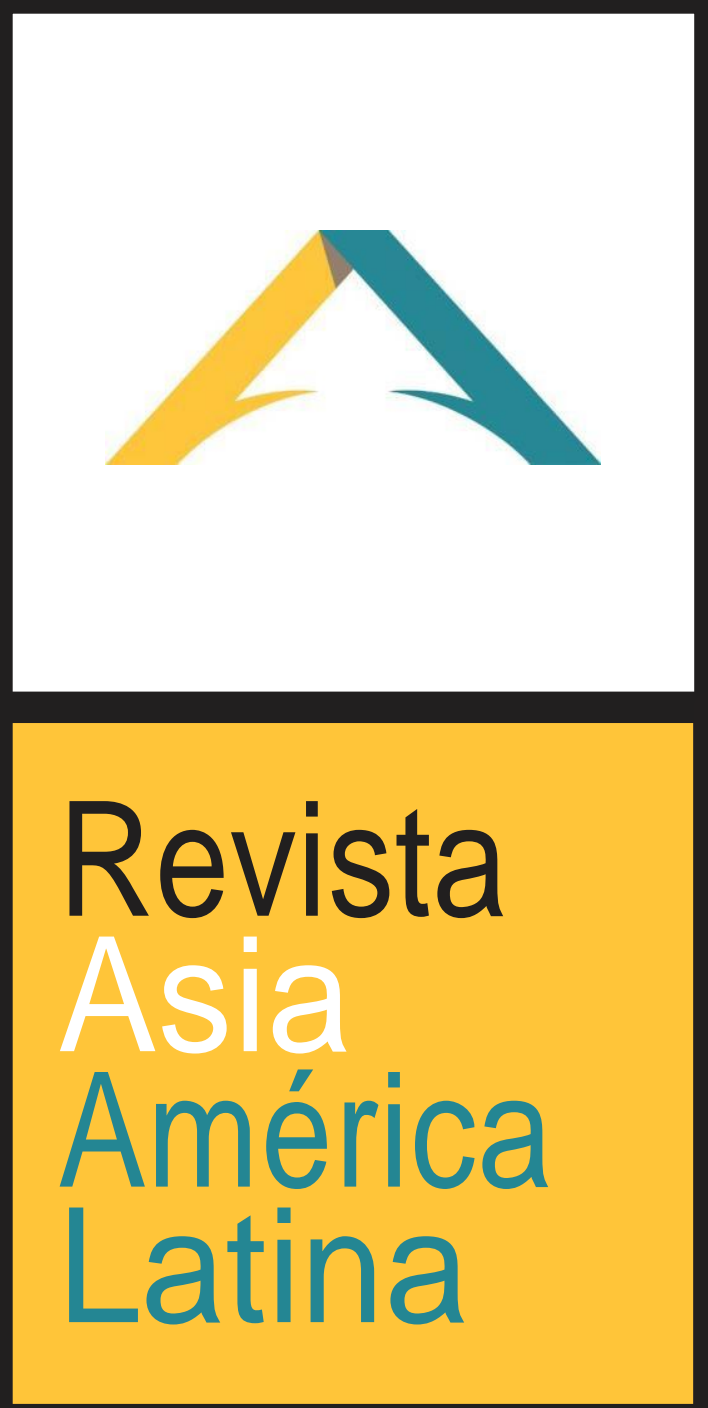

ISSN 2524-9347

Grupo de Estudios sobre Asia y América Latina Instituto de Estudios de América Latina y el Caribe Universidad de Buenos Aires

EU

DE BA 
La relación de la República Popular China y Taiwán con América Latina: el caso de

Paraguay

ESTEFANÍA ROUCO

\title{
LA RELACIÓN DE LA REPÚBLICA POPULAR CHINA Y TAIWÁN CON AMÉRICA LATINA: EL CASO DE PARAGUAY
}

\author{
THE RELATIONSHIP OF THE PEOPLE'S REPUBLIC OF CHINA AND \\ TAIWAN WITH LATIN AMERICA: THE CASE OF PARAGUAY
}

\author{
Estefanía Rouco \\ Universidad del Salvador \\ estefania_rouco@hotmail.com
}

En las investigaciones que versan sobre la relación de la República Popular China (RPC) con América Latina, los autores suelen aclarar que es en esta región donde se patenta más claramente el histórico conflicto por el reconocimiento diplomático a China. El caso de Paraguay tal vez sea uno de los más curiosos de Latinoamérica y el Caribe: no osciló entre reconocer a Pekín o Taipéi — como sí lo hicieron Nicaragua y Santa Lucía - y mantiene su vínculo con Taiwán a pesar de que pertenece a un Mercado Común en donde sus socios reconocen y comercian permanentemente con la República Popular. Por estos motivos el presente trabajo indaga sobre los vínculos comerciales y diplomáticos que unen a Paraguay y Taiwán, dado que es relevante para comprender el actual panorama de la política internacional de la región de América del Sur respecto a la República Popular China y Taiwán.

La primera parte del trabajo inquiere en los vínculos entre América Latina y Taiwán, siendo que estos países reconocieron primero al gobierno nacionalista de Chiang Kai-shek a mediados del siglo XX. En la segunda parte el enfoque está puesto en el caso particular de Paraguay, que mantiene el reconocimiento a Taiwán —aunque sucesivos presidentes hayan planteado entablar relaciones con el gobierno de Pekín-; y en la relación Asunción-Taipéi en el marco regional del Mercado Común del Sur (Mercosur). La última parte del trabajo consta de la revisión de los problemas actuales en el marco de las exportaciones paraguayas y en el nuevo contexto pandémico global.

El trabajo es de corte cualitativo, basado en el análisis del caso de los lazos diplomáticos y económicos entre Paraguay y Taiwán. Sobre el uso de fuentes, se utilizaron artículos académicos, informes ministeriales y para los datos más recientes, notas periodísticas y comunicados de prensa. Para comprender mejor la situación actual de la relación entre Paraguay y Taiwán se recurrió a una introducción histórica sobre los lazos diplomáticos que unieron a Taiwán con la región de América Latina y el Caribe, añadiendo una tabla con información demográfica actualizada, y una figura con los datos económicos 
La relación de la República Popular China y Taiwán con América Latina: el caso de Paraguay

ESTEFANÍA ROUCO

oficiales más recientes sobre la situación de la balanza comercial de Paraguay respecto a Taiwán.

\section{La relación de América Latina y el Caribe con Taiwán a través de los años}

¿Dónde radica la importancia del reconocimiento de Paraguay al gobierno de Taipéi? La mayoría de los países que reconocen a Taiwán son países latinoamericanos, y Paraguay es el único de toda América del Sur. Solamente en los últimos cinco años y tomando en cuenta la región de América Latina y el Caribe, Taiwán perdió el reconocimiento de República Dominicana, El Salvador y Panamá; lo que ha reducido cada vez más el número de sus aliados diplomáticos a nivel mundial. De hecho, uno de los motivos que citó el Secretario de Comunicaciones de la presidencia salvadoreña como factor decisivo a la hora de establecer relaciones con la RPC fue la necesidad de estrechar lazos con la pujante economía china (Wallace, 2018).

Erikson y Chen (2007) consideran que América Latina es una de las regiones más presentes en la disputa diplomática entre Taiwán y la República Popular, porque es aquí donde se encuentra la mayor cantidad de Estados que han oscilado entre reconocer a uno u otro; y toda esta disputa se desarrolla en la región colindante con los Estados Unidos de América, cuyo gobierno mira con precaución los acuerdos de cooperación estratégica y militar que firmaron algunos países latinoamericanos con la República Popular China. Rodríguez supone que uno de los motivos de que Taiwán tenga el reconocimiento diplomático de pequeños países de la región del Caribe se debe a que el tamaño de estos hace que la posibilidad de realizar grandes negocios con la República Popular sea casi nula, porque no cuentan con la capacidad productiva necesaria para estos intercambios (Rodríguez, 2008). En contraste con esta situación, la Agencia de Noticias Xinhua publicó un informe sobre el intercambio comercial entre la República Popular China y América Latina y el Caribe, donde destacan el rol de las exportaciones de carne bovina de Brasil y Argentina — dos de los países más grandes de la región - como uno de los puntos fuertes en el crecimiento de los vínculos económicos entre los países mencionados (Xinhua, 2019).

Sin embargo, décadas atrás Taiwán tenía un gran apoyo a nivel mundial, cuando el gobierno nacionalista de Chiang Kai-shek supo ser un socio estratégico para el gobierno de los Estados Unidos, en plena posguerra y ya comenzando la Guerra Fría. En los primeros años tras la fundación de la República Popular, el único país de América Latina y el Caribe que reconocía a esta fue Cuba, en 1960; a pesar de ello, la relación entre ambos gobiernos comenzó a deteriorarse cuando el gobierno de Fidel Castro se alineó con las 
La relación de la República Popular China y Taiwán con América Latina: el caso de

políticas de la Unión Soviética (Rodríguez, 2008). En el caso de Paraguay, la relación diplomática formal con Taiwán comenzó en 1957, un poco más tarde que otros países de América Latina: por ejemplo, el comienzo de los lazos con Argentina fue en 1945, con Brasil en 1928 y con Perú en 1931.

Todo cambió en 1971, cuando el aislamiento internacional de la República Popular China llegó a su fin tras a pasar a ser miembro de la Organización de las Naciones Unidas y a ocupar un asiento permanente en el Consejo de Seguridad, potestad que antes había detentado Taiwán. La visita de Henry Kissinger a Pekín en 1971 y de Richard Nixon al año siguiente confirmó el reconocimiento del gobierno de Estados Unidos al principio de una sola China, que proclama la Republica Popular para afirmar su soberanía sobre el territorio de la isla de Taiwán (Bailey, 2002). Fue en esta década cuando la mayoría de los países cambiaron su reconocimiento de la República China a la República Popular China.

Tabla 1

Países que reconocen a Taiwán en América Latina y el Caribe

\begin{tabular}{lcc}
\hline País & $\begin{array}{c}\text { Año en que se } \\
\text { establecieron relaciones } \\
\text { diplomáticas }\end{array}$ & Población \\
\hline Haití & 1956 & 11.402 .528 \\
Paraguay & 1957 & 7.132 .538 \\
Guatemala & 1960 & 17.915 .568 \\
Nicaragua & $1962-1985,1990$ & 6.624 .554 \\
Honduras & 1965 & 9.904 .607 \\
San Vicente y las & 1981 & 110.940 \\
Granadinas & 1983 & \\
San Cristóbal y & $1984-1997,2007$ & 183.627 \\
Nieves & 1989 & 397.628 \\
Santa Lucía & Belice &
\end{tabular}

Fuente: Ministry of Foreign Affairs of Taiwan (2020) y World Population Review (2020).

El cambio en el reconocimiento no implicó el fin de las relaciones informales entre Taiwán y la mayoría de los países del mundo. Una de las estrategias del gobierno de Taipéi para seguir estando presente en las principales ciudades del mundo - y como alternativa a las embajadas y consulados - fue la apertura de Oficinas Comerciales, reconvertidas en la década de 1990 en Oficinas Comerciales y Culturales. Estas oficinas cuentan con división de asuntos consulares, asuntos económicos, de prensa y cultura y de ciudadanos de 
La relación de la República Popular China y Taiwán con América Latina: el caso de Paraguay

ESTEFANÍA ROUCO

ultramar (Oficina Comercial y Cultural de Taipéi en Argentina, 2020), por lo que son embajadas de facto.

El caso de Costa Rica es digno de ser mencionado, porque el entonces presidente Óscar Arias, tras anunciar en el año 2007 que se romperían las relaciones diplomáticas con Taiwán para establecerlas con la República Popular, declaró que esta decisión tenía base en un "realismo elemental", dado que tenían que "normalizar los vínculos con un país al que ya no podían ignorar", para así poder fortalecer los lazos comerciales con Pekín (El Mundo, 2007). Quedó patente que esta resolución tuvo un carácter pragmático y económico, no ideológico. Un ejemplo más reciente, pero con similares características, es el de Panamá, que estableció relaciones diplomáticas con la República Popular China en el año 2017. Las razones aludidas por el ex presidente Juan Carlos Varela, al igual que su par costarricense, fueron de índole económica. Siendo China uno de los usuarios más importantes del Canal y el principal importador de mercancías de la zona, el reconocimiento diplomático ya no podía retrasarse más (BBC Mundo, 2017).

Tomando como ejemplo comparativo a otro país de Latinoamérica que al igual que Paraguay actualmente reconoce a Taiwán, el devenir mismo de la política nicaragüense hizo que Managua reconociera primero a la República Popular en detrimento de Taiwán en 1985, para luego retomar la relación con Taiwán en 1990 tras la salida del poder de Daniel Ortega. Aunque Ortega regresó a la presidencia de Nicaragua en el año 2007, la falta de proyectos concretos de asistencia económica por parte de la RPC hizo que el reconocimiento a Taiwán se mantuviera. Esto pareció cambiar en el año 2012, cuando la República Popular comenzó a financiar la construcción de un canal interoceánico para unir el Océano Pacífico y el Océano Atlántico, rivalizando así con el Canal de Panamá. Este financiamiento levantó sospechas de ser parte de un proyecto estratégico del gobierno de Pekín para intervenir en la ruta comercial marítima de América Central, como parte de la iniciativa de la Franja y la Ruta (Grau Vila, 2016). Las obras nunca comenzaron y el empresario chino propietario de HKND, firma que contaba con la concesión, no volvió a aparecer en público. Si bien la fecha de inauguración original iba a ser el año 2020, el presidente nicaragüense anunció a fines del 2019 que el proyecto sería revivido (Deutsche Welle América Latina, 2019).

Del resto de los países de América Latina y el Caribe que reconocen a Taiwán, el gobierno de Taipéi ha sido uno de los principales benefactores en asistencia económica, incluso llegando a ser el principal otorgador de ayuda económica de San Vicente y las Granadinas y San Cristóbal y Nieves (Erikson y Chen, 2007). El Fondo de Desarrollo y Cooperación de Taiwán es el organismo encargado de organizar los proyectos de ayuda y cooperación con los países 
La relación de la República Popular China y Taiwán con América Latina: el caso de Paraguay

ESTEFANÍA ROUCO

socios, a través de proyectos de préstamos e inversiones, misiones médicas y asistencias técnicas (Lemus Delgado, 2017).

\section{El caso de Paraguay}

Arce (2011) considera que la relación de Paraguay con Taiwán es una herencia de la política exterior del expresidente Alfredo Stroessner, y que las presiones de la República Popular para obtener el reconocimiento por parte del gobierno de Asunción empezaron a ser cada vez más firmes durante el gobierno del expresidente Nicanor Duarte Frutos; cuando el gobierno de China continental comenzó a acercarse a la oposición paraguaya y a presionar a los socios de Paraguay en el Mercosur (Arce, 2011). Luego del triunfo de Lugo se habló de un posible acercamiento a Pekín, respaldado por trabajos académicos que calculaban las circunstancias de un futuro establecimiento de relaciones diplomáticas con China continental (Diéguez Suarez, 2008). Javier Diéguez Suarez evaluó la relación de Paraguay con Taiwán y la República Popular tras la asunción de Lugo a la presidencia, resaltando algunos factores que serían decisivos para un cambio en el plano del reconocimiento diplomático: las expectativas del empresariado paraguayo, el desprestigio de la ayuda económica taiwanesa —asociado a casos de corrupción en el seno del partido Coloradoy una afinidad ideológica entre Lugo y el gobierno del Partido Comunista de China. No obstante, este acercamiento de la presidencia de Lugo a Pekín fue abandonado por la tregua existente en ese entonces entre los gobiernos de la RPC y Taiwán (Arce, 2011).

Dos de las estrategias más importantes para afianzar los lazos entre Taiwán y los países que la reconocen son las ayudas económicas y técnicas, mediante el otorgamiento de préstamos, donaciones, inversiones y asistencias tecnológicas; y las visitas de alto nivel entre funcionarios de los respectivos gobiernos. Estas políticas no han variado más allá del cambio de signo político entre los distintos gobiernos taiwaneses, en la alternancia entre el Kuomintang (KMT) y el Partido Progresista Democrático (PPD). En el caso de Paraguay, este país es uno de los más beneficiados con becas para estudios de grado y posgrado en Taiwán (Rodríguez, 2008), y con préstamos, concesiones e inversiones (Mendelson Forman y Moreira, 2008). De hecho, la nueva sede del Congreso paraguayo, inaugurada en el año 2003, fue financiada con una donación de 20 millones de dólares estadounidenses del gobierno taiwanés. La presencia taiwanesa se asoma en el paisaje urbano de Asunción: en la capital paraguaya se encuentra el monumento en honor a Chiang Kai-shek más grande del mundo fuera de Taiwán, y también una avenida de la ciudad lleva su nombre.

Los datos más recientes del Ministerio de Hacienda del Paraguay sobre el comercio con Taiwán están comprendidos en el informe del período 2010- 
La relación de la República Popular China y Taiwán con América Latina: el caso de

2017, y demuestran un acercamiento en el equilibrio de la balanza comercial bilateral:

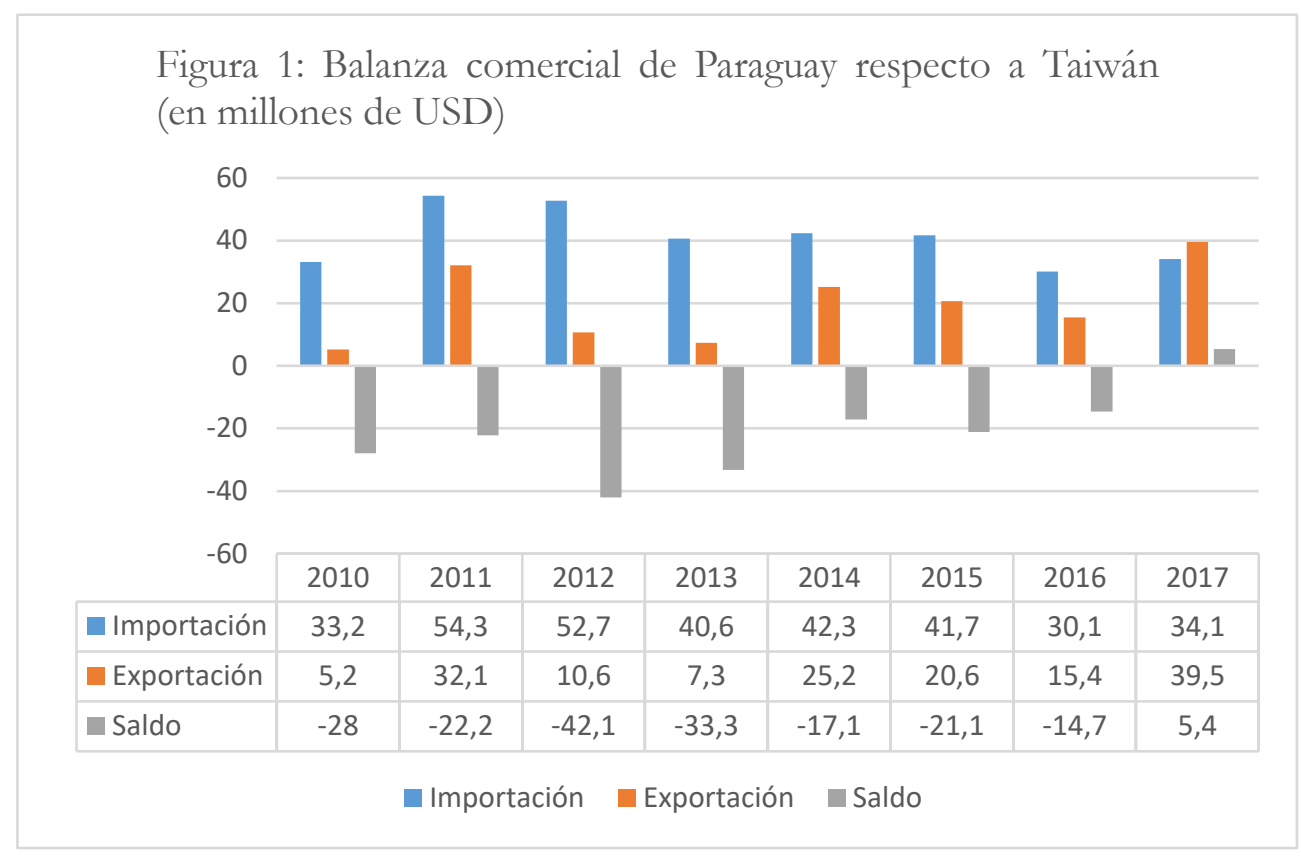

Figura 1. Fuente: elaboración propia en baso a datos del Ministerio de Hacienda de la República de Paraguay (2018)

En los últimos años, el conflicto entre el reconocimiento a la República Popular o a Taiwán se trasladó al campo económico, y esta situación no fue la excepción en Paraguay. Este país podría cumplir las necesidades de importación que requiere la República Popular, ya que produce commodities que son demandados por China, pero es considerado un país vetado para proveer materias primas por su reconocimiento a Taiwán (Slipak, 2014). Este veto no significa que China no le venda productos manufacturados a Paraguay, de hecho es la mayor fuente de importaciones de los últimos años, anteponiéndose a los principales socios comerciales: Brasil y Argentina (The Observatory of Economic Complexity, 2018). Por lo tanto, el gran caudal de importaciones chinas, con la contracara del veto a las exportaciones paraguayas, genera un gran desbalance en la balanza comercial.

La histórica relación entre Paraguay y Taiwán genera controversias en el marco de los países miembros del Mercosur. Durante el gobierno de Duarte Frutos, Argentina y Brasil reconocieron a la República Popular China como una "economía de mercado", sin consultar previamente con sus socios comerciales 
La relación de la República Popular China y Taiwán con América Latina: el caso de Paraguay

ESTEFANÍA ROUCO

regionales. Este reconocimiento generó que el vicecanciller paraguayo declarara que la relación con China no podía afectar el vínculo Asunción-Taipéi, y que por estos motivos no acompañaría un acuerdo entre la RPC y el Mercosur (Burdman, 2005).

En el año 2016 el presidente uruguayo Tabaré Vázquez viajó a Pekín con la idea de comenzar un diálogo para concretar un Tratado de Libre Comercio (TLC) con la República Popular China; necesitando la aprobación del resto de los miembros del Mercosur para poder alcanzar la firma del mismo. Aunque esta idea generó resistencia entre los industriales brasileños y argentinos, el principal motivo por el cual se consideraron paralizadas las negociaciones fue que el vínculo entre Asunción y Taipéi obstruía el avance de ellas (Cambiaso, 2016). Las mismas razones que impiden la firma de un TLC entre los países del Mercosur y la República Popular se aplican para la firma de un tratado de similares características entre Paraguay y Taiwán: aunque las conversaciones comenzaron en el año 2005, la membresía paraguaya en el Mercosur obstaculizó las negociaciones (Bernal, 2018).

En las últimas dos décadas una de las principales estrategias de vinculación económica de la República Popular China con los países de América Latina es la inversión extranjera directa (IED) (Ortiz Velázquez, 2017). El crecimiento de la economía china implicó una ampliación en la demanda de materias primas, de las que muchos países latinoamericanos son productores. Orozco Suárez (2018) encuentra que esta relación genera un modelo frágil, donde los exportadores dependen de la estabilidad del precio de los productos primarios pero a cambio reciben muchas importaciones chinas que compiten directamente con los productos manufacturados locales. Malamud (2007) considera que una de las cosas que espera la República Popular de América Latina, además de que esta garantice el flujo comercial de productos primarios, es el reconocimiento a China continental para así aislar políticamente a Taiwán. En los últimos tres años, la IED china se desaceleró gradualmente en la región: algunos países, como Argentina y Brasil —que históricamente recibían el mayor porcentaje—, fueron los más perjudicados por este cambio, lo que lleva a que Bauer y Cuéllar (2019) supongan que la razón de la desaceleración sean los problemas en las economías internas de estos países.

\section{Problemáticas actuales}

El ex encargado de negocios de la Embajada paraguaya en Taiwán, el Mg. Carlos Fleitas, declaró en el año 2017 que uno de los puntos principales de unión entre Paraguay y Taiwán es la convergencia en ideales sobre una Política de Cooperación para el Desarrollo — que busca asegurar la prosperidad y el bienestar de ambas naciones-, así como nociones similares sobre calidad 
La relación de la República Popular China y Taiwán con América Latina: el caso de

democrática y económica. Por estos motivos, Fleitas consideró que estas metas se hicieron patentes en los más de 70 acuerdos económicos y en las facilidades en otorgamiento de visados e intercambios de estudiantes (Secretaría Técnica de Planificación del Desarrollo Económico y Social de la República de Paraguay, 2017). Justamente, uno de esos acuerdos gira en torno a la elevación en la cuota de exportación de carne paraguaya a la isla, quizás uno de los temas que mayor discusión genera entre el empresariado paraguayo, como se verá a continuación.

En el año 2019 se reabrió la polémica en torno a la inexistencia de las exportaciones a China cuando el titular de la Asociación Paraguaya de Productores y Exportadores de Carne declaró que era necesario ampliar el comercio con la RPC, alegando que Paraguay se estaba marginando de las ganancias que generan las ventas de carne a China, en comparación con las ventas que sí realizaron los otros países del Mercosur (Frutos, 2019). Esta situación generó que el embajador taiwanés declarara que la relación comercial entre Paraguay y la RPC existe, dado que en Asunción se encuentran muchísimos productos chinos importados, y que la condición de que Paraguay rompa lazos con Taiwán para reconocer a China y así poder exportar productos primarios al territorio chino viola las normas y protocolos de la Organización Mundial de Comercio (Pintos, 2019).

Frente a la imposibilidad de las exportaciones paraguayas a la República Popular sin existir un reconocimiento político previo, el economista miembro del Centro de Análisis y Difusión de la Economía Paraguaya Gustavo Rojas declaró en una entrevista que existe una vía alternativa para entablar una posible relación Paraguay-RPC sin perder los lazos con Taiwán: el establecimiento de una oficina comercial en Hong Kong y la vinculación con los bancos de desarrollo asiáticos (Díaz, 2019). Hong Kong es una de las regiones administrativas especiales de la República Popular, y por esta razón cuenta con un sistema económico distinto a China continental.

Además, la embajada taiwanesa en Asunción emitió un comunicado comparando la creciente demanda de productos primarios por parte de Taiwán, en contraposición con la contracción de las compras de otros países, y señalando la duplicación de la compra de carne paraguaya entre enero y abril de 2020 (Agencia de Información Paraguaya, 2020). Como respuesta a los reclamos anteriormente mencionados de los empresarios exportadores, el gobierno taiwanés decidió eliminar los cupos de importación de carne bovina paraguaya, enmarcando esta eliminación en el "trato preferencial que Taiwán otorga a Paraguay en forma única y exclusiva, como muestra de sincera amistad y sólido compromiso con la hermana nación paraguaya" (Agencia de Información Paraguaya, 2020). A raíz de la firma de este acuerdo, la carne vacuna paraguaya logró ingresar en las góndolas de una de las cadenas de internacionales de hipermercados más importantes de Taiwán, Carrefour, por lo que el embajador 
La relación de la República Popular China y Taiwán con América Latina: el caso de Paraguay

ESTEFANÍA ROUCO

paraguayo en Taiwán declaró que "toda esta producción se da con altos estándares de calidad que permiten al país ingresar a mercados premium como el taiwanés" (Ministerio de Industria y Comercio de la República de Paraguay, 2020), resaltando "las excelentes relaciones que existe entre nuestros países y agradeció a los importadores taiwaneses, la confianza depositada, para concretar este importante negocio" (Ministerio de Relaciones Exteriores de la República de Paraguay, 2020).

De cara a la epidemia del COVID-19, Taiwán realizó una fuerte campaña de donaciones de material sanitario a sus aliados internacionales, y Paraguay fue uno de los grandes beneficiarios. La página de la Embajada de Taiwán en Paraguay menciona en una nota que por ser un aliado diplomático de la isla se enviaron a Asunción mascarillas, termómetros infrarrojos y cámaras térmicas (Embajada de la República China en Paraguay, 2020). Dados los cuestionamientos del gobierno de Taipéi por el accionar de la OMS frente a la pandemia —organización de la que no es miembro— Taiwán continúa en la búsqueda de aliados internacionales para defender y promover su postura frente a la crisis sanitaria. Estas donaciones fueron destacadas por el embajador Bobadilla Guillén en la Ceremonia de Inauguración de la Asociación de Amistad Interparlamentaria de la República de China y Paraguay, que se realizó el día 21 de agosto. El embajador además declaró que "en los últimos años su Gobierno ha recibido mucha presión por parte del gobierno de Pekín y del sector empresarial paraguayo para establecer relaciones diplomáticas con China continental y cortar con Taiwán"; pero que el presidente Mario Abdo Benítez considera a Taiwán "un verdadero amigo de Paraguay" y que seguirá manteniendo el reconocimiento a la isla (RTI Español, 2020).

\section{Conclusiones}

De acuerdo con los datos de la Tabla 1, se puede observar que los países que actualmente reconocen a Taiwán en América Latina y el Caribe no tienen un número alto en materia poblacional, y en más de la mitad de los casos no llega al millón de habitantes. De hecho, la importancia del reconocimiento paraguayo también radica en que, entre los aliados diplomáticos de Taiwán en la región, Paraguay es uno de los que tiene mayor población. Según los datos de la Figura 1, la balanza comercial entre Paraguay y Taiwán está tendiendo a equilibrarse, y hasta a mostrar un superávit a favor del primero; sin embargo, Taiwán no cuenta con la capacidad de inversión y otorgamiento de préstamos de la RPCh.

De los préstamos y donaciones anteriormente mencionados se puede inferir que la estrategia de Taiwán con respecto a sus socios es ayudarlos económicamente a cambio de que estos la reconozcan internacionalmente, pero la presión política china y las posibilidades del gran mercado potencial que puede 
La relación de la República Popular China y Taiwán con América Latina: el caso de

ofrecer la República Popular está teniendo repercusiones en la relación de Taiwán con los países de América Latina y el Caribe.

En el caso de Paraguay, una de estas grandes presiones por reconocer a la República Popular está enmarcada en el contexto de su pertenencia al Mercosur, dado que la reticencia del gobierno de Asunción por romper lazos con Taipéi es visto por sus socios comerciales como una de las más importantes barreras que impiden la realización de sustanciales acuerdos comerciales con China.

Sin embargo, la parálisis actual generada por el retiro de Argentina de las negociaciones del tratado de libre comercio con Corea del Sur reveló la debilidad de la voluntad en materia de cooperación y coordinación económica en el seno de los propios miembros fundadores. Más allá del contexto regional, el Brexit también puso de manifiesto los problemas que están teniendo los organismos de integración regional a nivel global, y con el retiro de Estados Unidos del Acuerdo Transpacífico de Cooperación Económica y el reemplazo del Tratado de Libre Comercio de América del Norte por el Tratado entre México, Estados Unidos y Canadá se evidencia que muchos futuros vínculos comerciales entre países tomarían un sesgo bilateral.

El estado de la relación entre la República Popular China y Taiwán también condiciona el comportamiento que ambas tienen frente al establecimiento de lazos o ruptura con los países de América Latina. Como se mencionó anteriormente en el caso del gobierno de Lugo, durante el año 2011 se distendió la tirante relación entre la RPCh y Taiwán. La aparente cordialidad de Hu Jintao y Ma Yingjeou llevó a que la República Popular no presionara al presidente paraguayo para que rompiera los vínculos diplomáticos con Taiwán.

Muy distinto es el panorama del año 2019, con las presidencias de Xi Jinping y Tsai Ing-wen. La crisis en Hong Kong, la reticencia del PPD — partido gobernante en Taiwán- de aceptar el Principio de Una Sola China y la reelección de Tsai como presidenta — cuando los sondeos de los meses anteriores señalaban como ganador al KMT, que tiene una mejor relación con China continental- llevaron a un grave deterioro en la relación entre ambos márgenes del Estrecho de Taiwán. No es casual que en ese mismo año comenzaran las fuertes presiones por parte de Pekín para que Paraguay reconociera a la RPC, cortando así los lazos diplomáticos con Taiwán, bajo el amparo del potencial mercado chino para las exportaciones paraguayas.

Aunque la relación entre la República Popular y Taiwán es cambiante, las políticas internas de ambos gobiernos respecto a las estrategias de relación con sus aliados diplomáticos siguen teniendo continuidad, más allá de que el signo político del gobierno taiwanés se alterne entre el PPD y el KMT.

El desafío se presenta similar para los otros países de América Latina que reconocen a Taiwán. En el ejemplo de Nicaragua, la futura inversión china en la 
La relación de la República Popular China y Taiwán con América Latina: el caso de Paraguay

ESTEFANÍA ROUCO

construcción de un gran canal interoceánico suscitó dudas sobre el posible establecimiento de lazos diplomáticos entre Nicaragua y la República Popular China. La continua cooperación económica con Taiwán frente a la inversión incierta de China hizo que el statu quo se mantuviera hasta el día de hoy.

A diferencia del establecimiento o ruptura de relaciones diplomáticas durante el período de la Guerra Fría, en el contexto actual los analistas citados en el trabajo no mencionan el factor ideológico como decisivo en los vaivenes de las relaciones de los países latinoamericanos con la República Popular y Taiwán. El recambio democrático lleva a que gobiernen distintos partidos, pero para los gobiernos de América Latina, las promesas de inversiones y préstamos son más importantes que las banderas ideológicas del PCC, el KMT y el PPD.

Si bien la República Popular en uno de los principales compradores de materias primas del mundo, el modelo de compra de commodities y venta de productos manufacturados generó una balanza comercial desequilibrada en los principales países del Cono Sur. La creencia de que Paraguay no tiene vínculos comerciales con la República Popular es falsa, dado que es el mayor importador de bienes manufacturados en Paraguay. Lo que Paraguay aún no ha logrado alcanzar es poder exportar carne bovina a China continental.

La reciente respuesta del gobierno taiwanés a las demandas de ampliación de cupos para la venta de carne bovina paraguaya demuestra que Taipéi es receptiva a los reclamos de sus aliados; especialmente en un marco de pandemia del COVID-19, donde las consecuencias económicas en el contexto internacional todavía no son certeras.

\section{Referencias bibliográficas}

ArCE, L. (2011). En la búsqueda de una estrategia global: La Política Externa del Paraguay. Cuadernos sobre Relaciones Internacionales, Regionalismo y Desarrollo, 6(11), pp. 105-127.

Bailey, P.J. (2002). China en el siglo XX. Ariel Pueblos, Barcelona, pp. 203-204.

BAUER, S. Y CUÉLLAR, A. (17 de abril, 2019). Se desacelera la inversión extranjera directa china hacia América Latina. Recuperado de: https://dialogochino.net/es/comercio-y-inversiones-es/25775-sedesacelera-la-inversion-extranjera-directa-china-hacia-america-latina/

BBC MunDO. Por qué Panamá rompió su vínculo histórico con Taiwán y estableció relaciones diplomáticas con China (13 de junio, 2017).. Recuperado de: https://www.bbc.com/mundo/noticias-america-latina40256859

Bernal, P. (29 de julio, 2018). Paraguay and Taiwan: An unlikely but fruitful relationship. Latin America Post. Recuperado de: 
La relación de la República Popular China y Taiwán con América Latina: el caso de Paraguay

ESTEFANÍA ROUCO

https:/ / latinamericanpost.com/22323-paraguay-and-taiwan-anunlikely-but-fruitful-relationship

Burdman, J. (2005). América Latina en la última batalla diplomática ChinaTaiwán. Quórum: revista de pensamiento iberoamericano ${ }^{\circ}$ 12. pp. 211-221.

Cambiaso, F. (2016). Relaciones de Paraguay con Taiwán impiden TLC regional con China. Recuperado de https://ecos.la/UY/9/actualidad/2016/10/29/8885/relaciones-deparaguay-con-taiwan-impiden-tlc-regional-con-china/

COSTA RICA ESTABLECE RELACIONES CON CHINA Y 'ROMPE' CON TAIWÁN TRAS 60 AÑos (7 de junio, 2007). El Mundo. Recuperado de: https://www.elmundo.es/elmundo/2007/06/07/internacional/11811 74880.html

Deutsche Welle América Latina (14 de agosto, 2019). Ortega revive proyecto de canal interoceánico en Nicaragua. DW Noticias. Recuperado de: $\quad$ https://www.dw.com/es/ortega-revive-proyecto-de-canalinteroce $\%$ C3\%A1 nico-en-nicaragua/a-50019224

DíAZ, D. (11 de septiembre, 2019). ¿Qué oportunidades tiene Paraguay de ingresar al mercado chino? Recuperado de https://infonegocios.com.py/nota-principal/que-oportunidades-tieneparaguay-de-ingresar-al-mercado-chino

Diéguez SuÁreZ, J. (2008). Paraguay entre Beijing y Taipéi. The Business Way $\mathrm{N}^{\mathrm{O}} 3 . \quad$ Recuperado de: http://thebusinessways.blogspot.com.es/2008/06/paraguay-entrebeijing-y-taipei.html

Embajada de la República China en TAiWÁn (23 de abril, 2020). Taiwán dona mascarillas médicas para la lucha contra el Covid-19. Recuperado de: https://www.roc-taiwan.org/py_es/post/14317.html

ERIKSON, D. Y CHEN, J. (2007). China, Taiwan, and the Battle for Latin America. Fletcher Forum of World Affairs Vol. 31(2), pp. 69-89.

FRUTOS, L. (4 de noviembre, 2019). El problema no es Taiwán, es Paraguay, nos estamos automarginando de la segunda economía mundial. Infonegocios Paraguay. Recuperado de https://infonegocios.com.py/infoganaderia/el-problema-no-es-taiwanes-paraguay-nos-estamos-automarginando-de-la-segunda-economiamundial

Grau ViLA, C. (2016). Entre China y Taiwán: el caso de Nicaragua y el Gran Canal Interoceánico. Revista CIDOB d'Afers Internacionals n ${ }^{\circ} 114$, p. 207 231.

Lemus Delgado, D. (2017). La Ayuda Oficial al Desarrollo de Taiwán en América Latina a la sombra de China: Entre la identidad nacional y el 
La relación de la República Popular China y Taiwán con América Latina: el caso de Paraguay

ESTEFANÍA ROUCO

reconocimiento internacional. Revista Internacional de Cooperación $y$ Desarrollo n ${ }^{\circ}$ 4, pp. 51-67.

Malamud, C. (2007). Los actores extrarregionales en América Latina (I): China. Documento de trabajo n̊50, Real Instituto Elcano, pp 1-15.

Mendelson Forman, J. y Moreira, S. (2009). Taiwan-China Balancing Act in Latin America. En McGiffert, C. (Ed.), Chinese soft power and its implications for the United States (pp. 102-115). Washington DC: Center for Strategic and International Studies

Ministerio de Hacienda de la República de Paraguay (2018). Comercio bilateral Paraguay Taiwán, período 2010-2017. Recuperado de: https: / $/$ www.google.com/url?sa $=\mathrm{t \& rct}=\mathrm{j} \& \mathrm{q}=\&$ esrc $=\mathrm{s} \&$ source $=$ web\& cd=\&ved=2ahUKEwjMl7SGzePpAhV2HbkGHb8bBRwQFjAAegQI BBAB\&url=http $\% 3 \mathrm{~A} \% 2 \mathrm{~F} \% 2 \mathrm{Fwww} \cdot$.economia.gov.py $\% 2$ Findex.php $\%$ 2Fdownload_file\%2Fview\%2F1986\%2F352\&usg=AOvVaw29cehvbw _OtsJeFOK-B0Kf

Ministerio de Industria y Comercio de la República de Paraguay (21 de agosto, 2020). Carne paraguaya en Carrefour, Taipei. Recuperado de: http://www.mic.gov.py/mic/w/contenido.php?pagina=1\&id=1646

Ministerio de RELACIONES EXTERIORES DE LA REPÚBLICA DE PARAGUAY (21 de agosto, 2020). Carne paraguaya ya se vende en la cadena de supermercados de Taiwán. Recuperado de: https://www.mre.gov.py/index.php/noticiasde-embajadas-y-consulados/carne-paraguaya-ya-se-vende-en-la-cadenade-supermercados-de-taiwan

Ministry of Foreign AfFairs, Republic of China TAiwan (2020). Diplomatic Allies. Recuperado de: https://www.mofa.gov.tw/en/AlliesIndex.aspx?n=DF6F8F246049F8 D6\&sms $=$ A76B7230ADF29736

Oficina Comercial y Cultural De TAipé I EN ARgENTiNa (2020). Información general de la Oficina Comercial y Cultural de Taipéi en Argentina. Recuperado de https://www.roc-taiwan.org/ar_es/post/4043.html (mayo de 2020)

Orozco SuÁrez, C.R. (2018). El papel de la IED China en América Latina y el Caribe: ¿Cooperación Sur-Sur? Papeles De Europa n³1, pp. 57-68.

ORTIZ VELÁSQUEZ, S. (2017). Inversión Extranjera Directa de China en América Latina y el Caribe, aspectos metodológicos y tendencias durante 20012016. Economía Informa Vol. 406, pp. 4-17.

PINTOS, L. (6 de diciembre, 2019). China extorsiona y falta al respeto a un país soberano como Paraguay. Recuperado de: https://www.lanacion.com.py/politica_edicion_impresa/2019/12/06/ china-extorsiona-y-falta-al-respeto-a-un-pais-soberano-como-paraguay/

Rodríguez, M. (2008). La batalla diplomática de Beijing y Taipei en América Latina y el Caribe. Revista Cidob d'Afers Internacionals nº81, pp. 209-231. 
La relación de la República Popular China y Taiwán con América Latina: el caso de

El PResidente Paraguayo Mario AbDo Benítez deFiende la AMistad CON TAIWÁN (21 de julio, 2020). RTI Español. Recuperado de: https://es-wp.rti.org.tw/archivo/748175 (agosto de 2020)

Secretaría TéCnica de Planificación del Desarrollo EConómico y Social de la República de Paraguay (13 de julio, 2017). Paraguay y Taiwán cumplen 60 años de cooperación y alianza para desarrollo de sus pueblos. Recuperado de: http://www.stp.gov.py/v1/paraguay-y-taiwancumplen-60-anos-de-cooperacion-y-alianza-para-desarrollo-de-suspueblos/

SLIPAK, A. (2014). América Latina y China: ¿cooperación Sur-Sur o «Consenso de Beijing»? Nueva Sociedad $\mathrm{n}^{\circ} 250$. Recuperado de: https:// nuso.org/articulo/america-latina-y-china-cooperacion-sur-suro-consenso-de-beijing/

TAIWÁN REITERA SU APOYO A PARAGUAY CON FLEXIBILIZACIONES PARA EXPORTACIÓN DE CARNE A SU MERCADO (26 de mayo, 2020). Agencia de Información Paraguaya. Recuperado de: https://www.ip.gov.py/ip/taiwanreitera-su-apoyo-a-paraguay-con-flexibilizaciones-para-exportacion-decarne-a-su-mercado/

The Observatory of Economic Complex (2018). Paraguay: exportación, importación y balanza comercial. Recuperado de: https://oec.world/es/profile/country/pry/

VOLUMEN DE COMERCIO CHINA-AMÉRICA LATINA SUPERA 300.000 MILLONES DE DÓLARES EN 2018 (2 de enero, 2019). Xinhua Español. Recuperado de: http://spanish.xinhuanet.com/2019-02/01/c_137792833.htm

WALlaCE, A. (22 de agosto, 2018). ¿Diplomacia de chequera? Por qué quedan países en Centroamérica que no rompen relaciones con Taiwán a favor de China. BBC Mundo. Recuperado de: https://www.bbc.com/mundo/noticias-america-latina-40264113

World Population Review (2020). Countries That Recognize Taiwan 2020. Recuperado de https://worldpopulationreview.com/countries/countries-thatrecognize-taiwan/ 

